\title{
Wie kein anderer
}

In dieser Ausgabe widmen wir uns der Hochleistungskeramik und ihren Anwendungsmöglichkeiten in den Bereichen Energie- und Umwelttechnik. Es zeigt sich: Die Einsatzgebiete sind genauso vielfältig wie die Eigenschaften dieses außergewöhnlichen Werkstoffs. Er ist besonders verschleißfest und auch hohe Temperaturen und korrosive Medien können ihm nichts anhaben.

Das macht Hochleistungskeramik zu einem unersetzbaren Bestandteil von Elektroautos. In Form von piezokeramischen Sensoren, Isolierkomponenten oder als Gleitlager, aber auch beim Wärmemanagement der Leistungselektronik spielt Keramik hier eine wichtige Rolle.

Hochleistungskeramik ist auch eine Komponente der immer beliebteren E-Bikes. Jeder, der schon einmal eines gefahren ist weiß, dass man damit unter guten Bedingun- gen einen Rennradfahrer einholen kann. Mit den neuen Höchstgeschwindigkeiten müssen sich die schwereren E-Bikes aber auch umso effektiver abbremsen lassen. Dabei sind die richten Bremsscheiben für eine hohe Bremsleistung entscheidend. Keramische Faserverbundwerkstoffe machen das Pedelec zu einem sichereren Verkehrsmittel im Straßenverkehr und im Gelände.

Übrigens ist Hochleistungskeramik auch ein nützlicher Helfer in unserem Alltag: So können wir in Zukunft vielleicht auf intelligente Zahnimplantate zählen, die uns mitteilen, wann wir zum Zahnarzt müssen, während uns Fliesen mit Selbstreinigungseffekt das Putzen abnehmen.

Das breite Themenspektrum dieser Ausgabe beweist also einmal mehr: Keramik ist ein Werkstoff wie kein anderer.

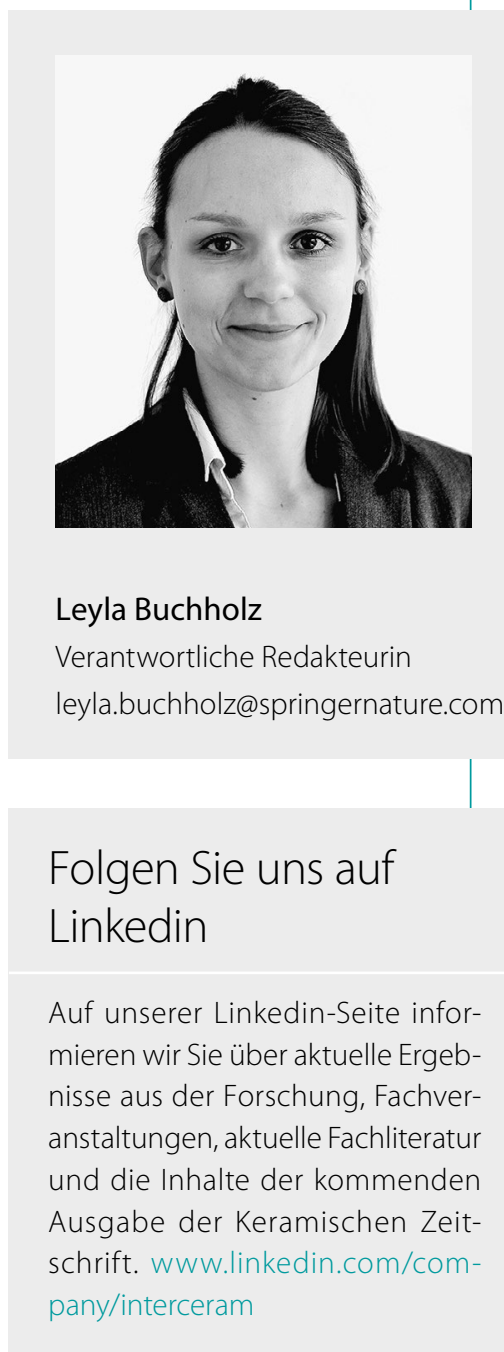

